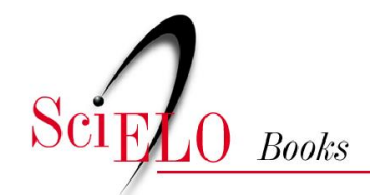

(M) Mackenzie

\title{
O desenvolvimento da Faculdade de Arquitetura e Urbanismo da Universidade Presbiteriana Mackenzie nas décadas de 1980 e 1990
}

\author{
Roberto Righi \\ Luiz Guilherme Rivera de Castro \\ Silvio Stefanini Sant'Anna \\ Eleana Patta Flain
}

\section{SciELO Books / SciELO Livros / SciELO Libros}

RIGHI, R., et al. O desenvolvimento da Faculdade de Arquitetura e Urbanismo da Universidade Presbiteriana Mackenzie nas décadas de 1980 e 1990. In: ALVIM, ATB., ABASCAL, EHS., and ABRUNHOSA, EC., orgs. Arquitetura Mackenzie 100 anos FAU-Mackenzie 70 anos: pionerismo e atualidade [online]. São Paulo: Editora Mackenzie, 2017, pp. 146-174. ISBN 978-85-8293-726-6. Available from: doi: 10.7476/9788582937266. Also available in ePUB from: http://books.scielo.org/id/xrrzx/epub/alvim-9788582937266.epub.

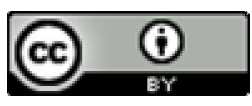

All the contents of this work, except where otherwise noted, is licensed under a Creative Commons Attribution $\underline{4.0 \text { International license. }}$

Todo o conteúdo deste trabalho, exceto quando houver ressalva, é publicado sob a licença Creative Commons Atribição 4.0.

Todo el contenido de esta obra, excepto donde se indique lo contrario, está bajo licencia de la licencia Creative Commons Reconocimento 4.0. 


\section{EVOLUÇÃO DA ESTRUTURA ACADÊMICA E ATUALIDADE}

(1980-2017)
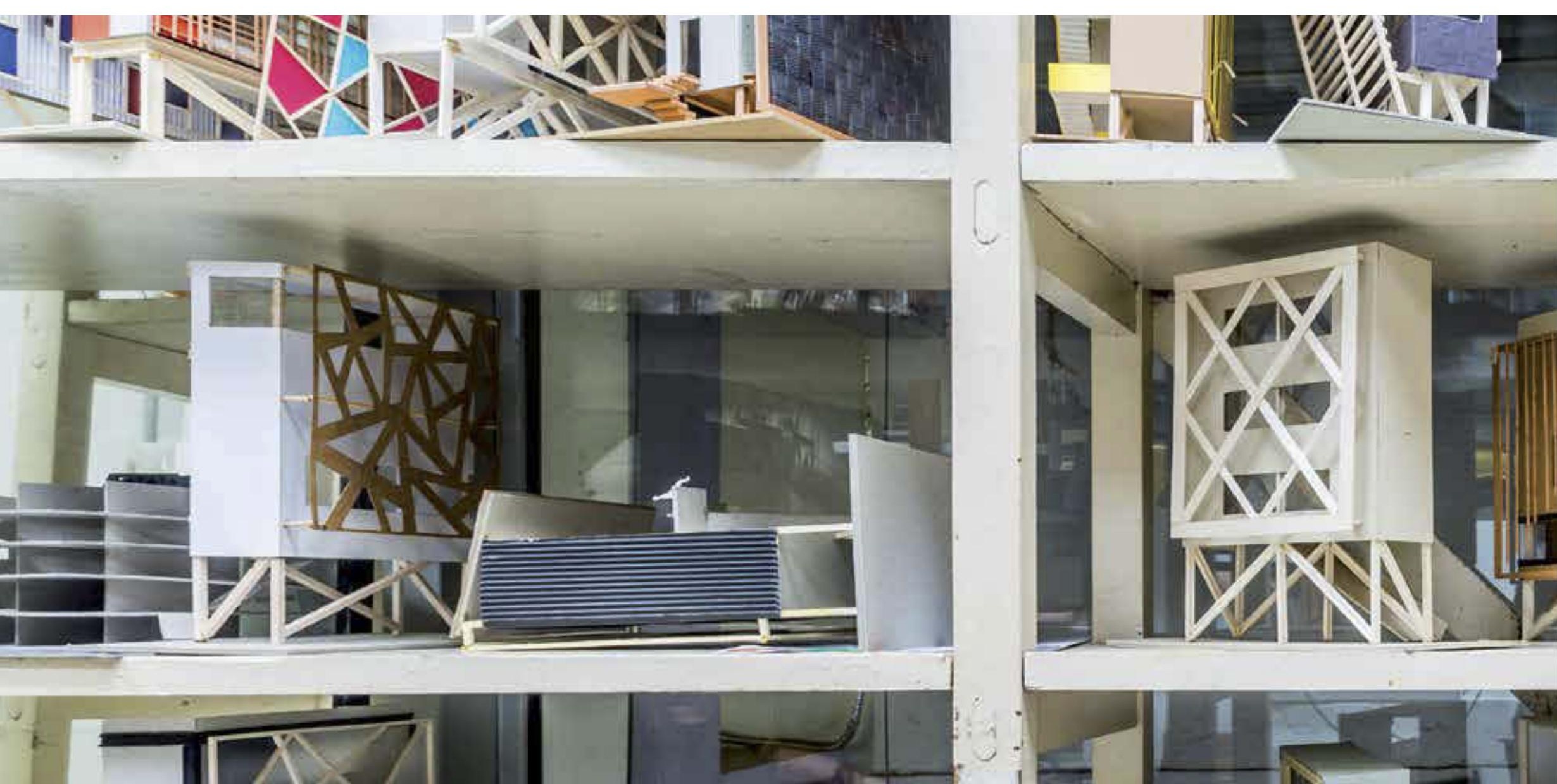

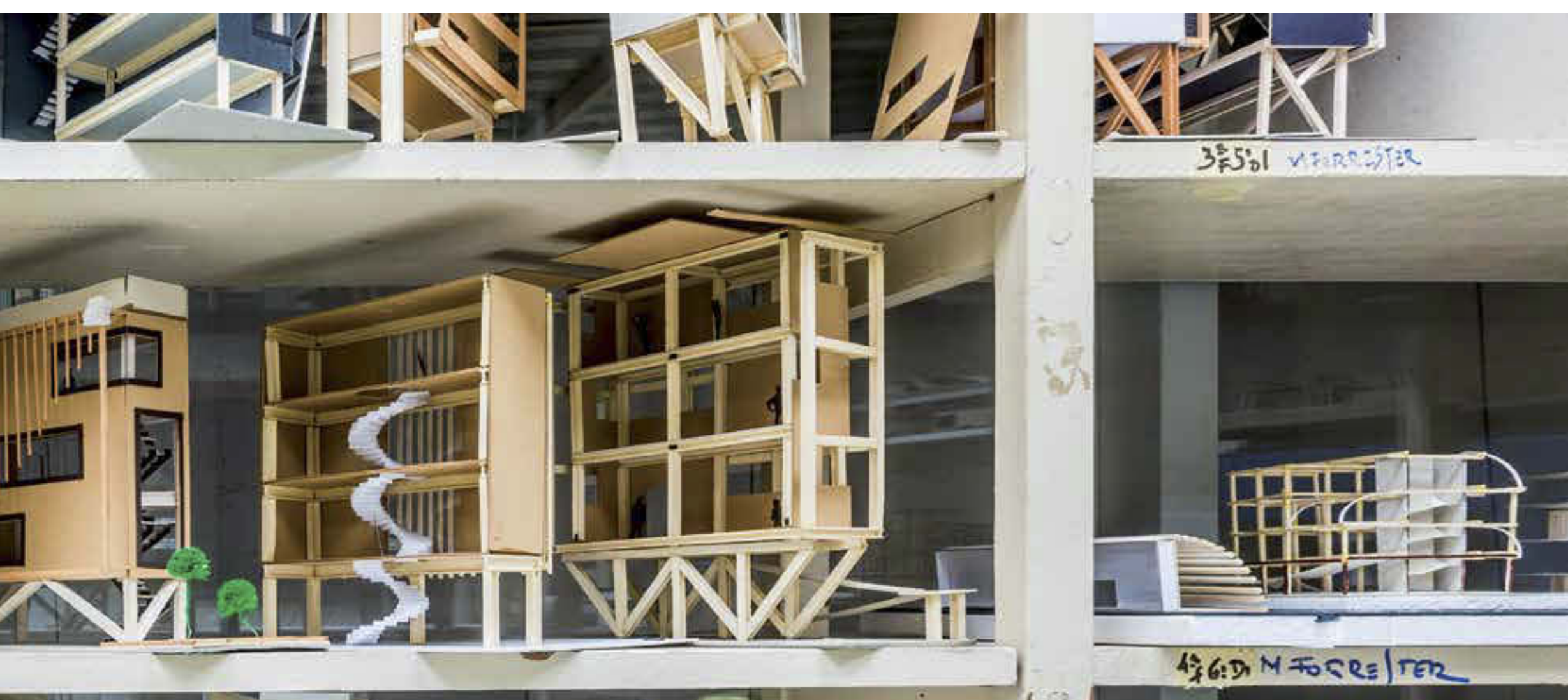

4F $6: D, M$ FO $S R E / T E R$ 
Inauguração, em 1998, da Sala de

Trabalho de Graduação Interdisciplinar

(TGI). Da esquerda para a direita,

Profs. Mario Figueroa, Ruth Verde

Zein, Denise Antonucci, Galba

Osório (Coordenador de TGI), Jun

Okamoto, Marcel Mendes, o então

discente Paulo Olivato (Presidente

do Dafam, hoje Professor na FAU-

Mackenzie), Walter Saraiva Kneese (o

então Diretor), Vera Osse, Francisco

Spadoni, Pedro Paulo de Melo Saraiva

e a discente Melissa Ribeiro (te-

soureira do Dafam). Atrás, os Profs.

Lauresto Couto Esher e Antonio Carlos

Sant'Anna Jr.

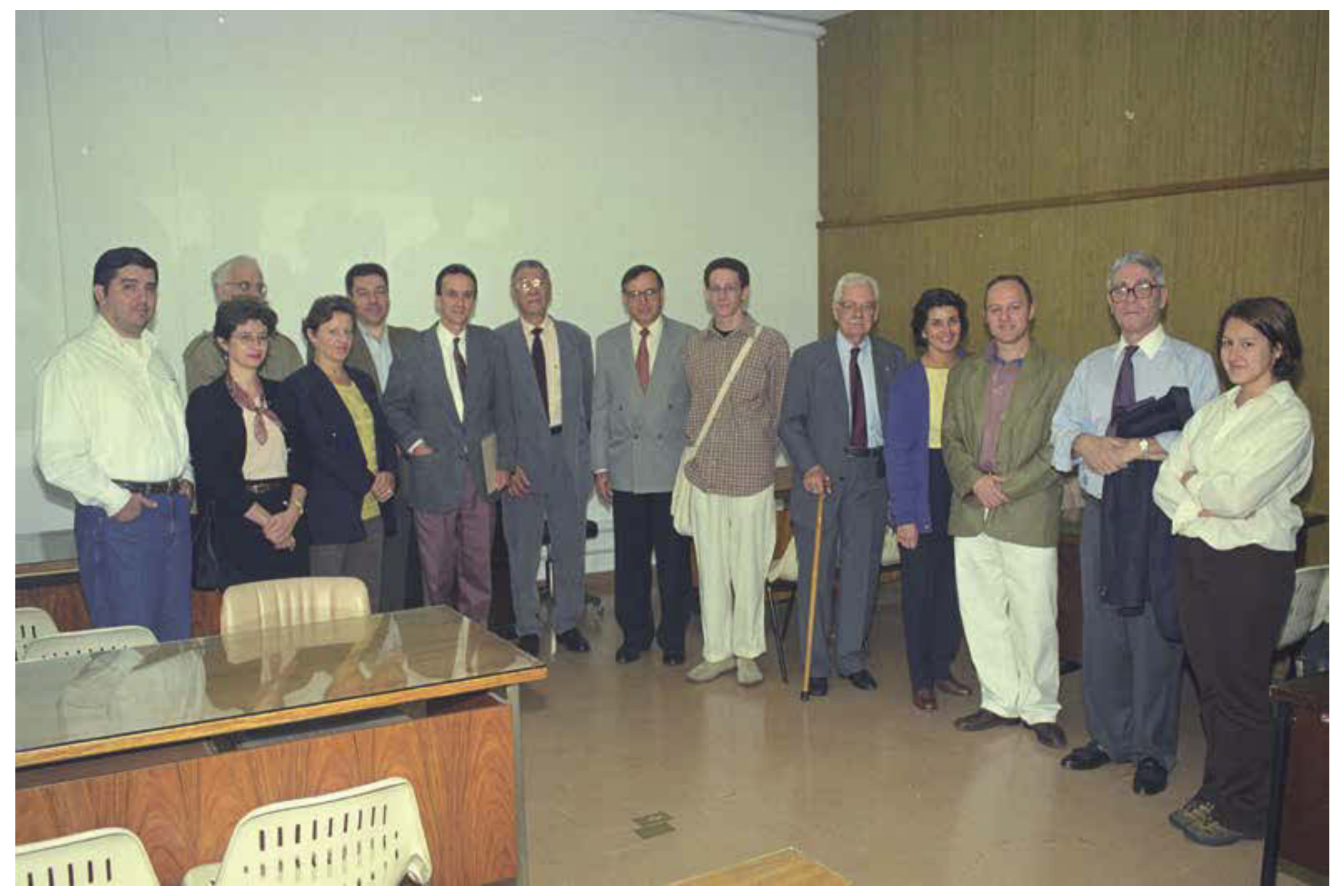




\section{O desenvolvimento da Faculdade de Arquitetura e Urbanismo da Universidade Presbiteriana Mackenzie nas décadas de 1980 e 1990}

Roberto Righi, Luiz Guilherme Rivera de Castro, Silvio Stefanini Sant'Anna, Eleana Patta Flain
1. A periodização estabelecida no Projeto Pedagógico 2003 da FAU-Mackenzie para o histórico dessa unidade de ensino distingue três períodos: de 1917 a 1947; de 1947 a 1960; de 1960 a 1970; e de 1970 até os dias de hoje (i. e. 2003). (UNIVERSIDADE MACKENZIE, 2003, p. 18).

A FAU-Mackenzie é uma das cinco Faculdades de Arquitetura pioneiras do Brasil, a primeira do estado de São Paulo, fundada em 1947. O conhecimento mais apurado de sua história é fundamental para uma adequada valorização de sua memória e orientação de seu desenvolvimento futuro. Sua história está fundamentada na criação, em 1917, do Curso de Engenheiros-Arquitetos, junto à Escola de Engenharia Mackenzie, seguida, em 1947, pela fundação da Faculdade de Arquitetura. ${ }^{1}$ No decorrer dos últimos 70 anos, as décadas de 1980 e 1990 foram pródigas em iniciativas, as quais tiveram grande repercussão em sua evolução no século XXI.

Este capítulo enfoca os aspectos mais relevantes para a compreensão dessas duas décadas. Inicia-se com o contexto da crise do desenvolvimento brasileiro e a efervescência cultural iniciada nos anos 1980, relacionada à renovação internacional da Arquitetura e Urbanismo e às mudanças provocadas pelo processo de abertura política que se iniciava. Na sequência, são apresentadas as principais reformas curriculares ocorridas na Graduação nas duas décadas mencionadas e a criação da Pós-Graduação Stricto Sensu em Arquitetura e Urbanismo, que é brevemente relatada, pois será tema de capítulo específico posteriormente. São também apresentados a criação e o desenvolvimento de dois departamentos de grande relevância: o de Planejamento Urbano e Urbanismo, e o de Tecnologia. Finalmente, destacam-se as exigências de titulação e de qualificação do corpo docente nesses tempos de transição, com impactos na formação e no exercício profissional do Arquiteto e Urbanista.

\section{O desenvolvimento brasileiro e a Arquitetura e Urbanismo nas décadas de 1980 e 1990}

O Brasil sofreu, a partir de 1975, os efeitos danosos do choque do petróleo. Essa situação foi progressivamente se agravando até que, no decorrer das décadas de 1980 e 1990, ocorreu o advento de uma dramática crise. Uma sucessão de pacotes econômicos desastrosos acirrou as contradições sociais e o crescimento das taxas de urbanização provocadas por migrações e o inchaço das grandes cidades. A configuração social se alterou e a economia urbana informal cresceu. O Estado não pôde mais assumir de forma competente o seu papel. Principalmente, o Poder Federal mudou com a Constituição de 1988, que possuí caráter mais localista, em contraposição às Constituições anterio- 
res, principalmente às da década de 1960. As mudanças no perfil da demanda de projetos arquitetônicos e de planos urbanísticos ocorreram com menor papel governamental. Tudo isso representava um imenso desafio para a atuação acadêmica e profissional dos Arquitetos e Urbanistas (RIGHI et al., 2002).

A Arquitetura adquiriu novas destinações e sua sustentação foi dirigida cada vez mais pela iniciativa privada, com crescente participação internacional. Os investimentos e o domínio de tecnologias avançadas por parte dos profissionais tornaram possível a sua distinção em um mercado altamente competitivo. A informatização progressiva dos processos de projetação tornou-se uma ferramenta necessária para a economia de tempo e a produção de maior quantidade de projetos a menores custos com mais qualidade, que se refletem na metodologia, na produção e na organização dos escritórios de Arquitetura. Também surgem novas demandas estético-formais, que acompanham as inovadoras demandas técnicas e de uso dos materiais (RIGHI et al., 2002).

Houve também, a partir de 1980, uma mudança paradigmática no desenvolvimento da Arquitetura brasileira, sobretudo da Arquitetura paulista. Verificaram-se mudanças dos referenciais teóricos, tais como: diversidade, heterogeneidade e pluralismo, resultantes da difusão do discurso crítico da pós-modernidade em oposição ao modernismo.

O Arquiteto em um mercado profissional na cidade global, em um país semiperiférico precisava refletir de forma crítica sobre a própria formação acadêmica e técnica. Naquele momento, ocorreu um forte aumento do número de profissionais, devido à proliferação dos cursos resultante do início do processo de privatização maciça do ensino universitário. A inserção profissional dos Arquitetos era, no início dos anos 1980 e 1990, principalmente no trabalho assalariado, contraposto ao profissional liberal do passado. Essa situação foi estimulada pela criação das empresas públicas e pelo crescimento das grandes consultorias e empreiteiras, que atuavam em prol do Estado no milagre brasileiro da década de 1970. No decorrer do período, houve a redução do papel do Estado. As realizações privadas privilegiaram o mercado em detrimento do sentido cultural e do atendimento das necessidades da sociedade como um todo.

As condições para a formação dos novos profissionais se agravaram com a explosão de muitos novos cursos particulares deficientes em corpo docente e instalações. Esse processo é acompanhado pelo sucateamento das universidades públicas, imersas na carência permanente de recursos e a perda acelerada de seus quadros docentes, devido à aposentadoria e aos baixos salários. Essa situação exigiu a rápida incorporação aos cursos de Arquitetura e Urbanismo de uma base consistente de conhecimentos históricos, de uma apreciação crítica das realidades sociais, econômicas e físico-ambientais e suas relações com o espaço construído, bem como uma inserção da universidade à realidade dos processos produtivos em aplicação (RIGHI, 2000). 
Ao mesmo tempo que recentemente se vive essa crise profissional, a Arquitetura internacional apresenta profundas mudanças qualitativas. No Brasil, a repercussão do processo de mudança paradigmática é lenta e descontínua, geralmente acompanhada pela falta de compreensão de sua real extensão e natureza, devido ao isolamento e ao saudosismo, que levam à persistência de padrões superados de um lado e de outro, um forte formalismo acompanhado da falta de reflexão crítica, que resulta em uma atitude forte do mercado imobiliário e por um design elitizado e desprovido de significado social. É necessário colocar-se em sincronia com a produção cultural internacional e, ao mesmo tempo, refletir sobre as matrizes culturais nacionais, criando uma produção original e contemporânea, corretamente engajada historicamente (RIGHI, 2000).

\section{Apesar da crise estrutural, a década de 1980 viveu a efervescência cultural na Arquitetura e Urbanismo}

Inúmeros eventos na cidade de São Paulo reuniam arquitetos representantes da vanguarda para apresentar projetos de Arquitetura, e seus discursos eram inspirados nos textos de Aldo Rossi, Robert Venturi, Paolo Portoghesi, ${ }^{2}$ entre outros. O contexto político também mudava com o enfraquecimento do Regime Militar, da censura e, finalmente, com as Diretas Já e a Constituição de 1988.

Apesar da flexibilização no regime político, ocorriam conflitos na comunidade acadêmica. Como exemplo, citamos a Moção n॰ 255 de 25 de agosto de 1983 do vereador Lauro Ferraz e de outros em solidariedade aos estudantes da Universidade Mackenzie na luta pela democratização da Universidade. A razão do problema foi a proibição da "Semana Charles Darwin" (CÂMARA MUNICIPAL, 1983).

Os estudantes de Arquitetura da FAU-Mackenzie eram presença garantida em eventos que traziam novas visões e paradigmas. O primeiro must de Arquitetura foi realizado no auditório da Fundação Getulio Vargas, entre 10 e 13 de junho de 1985, com a presença de arquitetos que teriam grande relevância no cenário das transformações, como Pitanga do Amparo, Marlene Acayaba, Sergio Prado, Anne Marie Sumner (que se tornaria professora da FAU-Mackenzie), e os egressos Carlos Bratke (Mackenzie, 1967), Roberto Loeb (Mackenzie, 1965), Tito Livio Frascino (Mackenzie, 1964) e Vasco de Mello (Mackenzie, 1964), ambos da Central de Projetos, e Vitor Lotufo, vários deles também professores. O congresso internacional "Cidades do Futuro", realizado no Palácio das Convenções do Anhembi, entre 26 e 30 de agosto de 1985, contou com a presença de Arquitetos estrangeiros, como Helge Bofinger, da Alemanha, Charles Moore, dos Estados Unidos, Yona Friedman, da França, Peter Cook, da Inglaterra, Alfonso Grassi, da Itália, Kenzo Tange, do Japão, Jorge Goldemberg, da Argentina, e brasileiros, como Oscar Niemeyer, Rosa Kliass, Roberto Burle Marx e o egresso da FAUMackenzie e eminente Arquiteto urbanista Jorge Wilheim (Mackenzie, 1952), entre outros.
2. Arquitetos e teóricos de grande relevância para a compreensão da Arquitetura nas décadas de 1960, 1970 e 1980: Aldo Rossi é o autor de Arquitetura da cidade (1966); Robert Venturi escreveu com a Arquiteta Denise Scott Brown obras seminais, tais como Complexidade e Contradição em Arquitetura, originalmente publicada em 1966, e ambos com Steven Izenour publicaram Aprendendo com Las Vegas, em 1972; Paolo Portoghesi é o autor de Depois da Arquitetura Moderna (Dopo L'Architettura Moderna, 1980). 


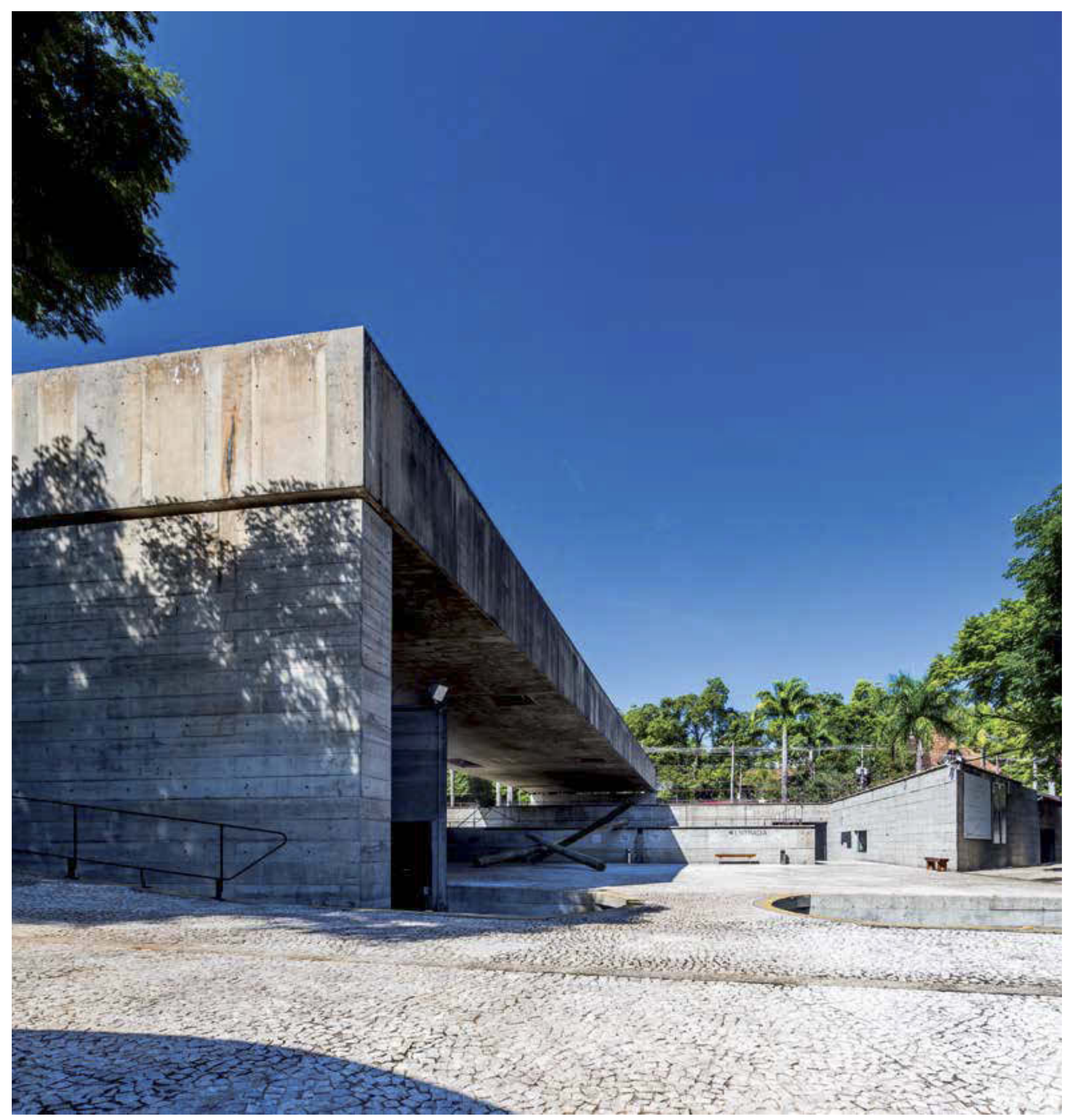


Outro evento importante denominado "Tendências na Arquitetura Brasileira Contemporânea" realizou um ciclo de debates promovido e sediado pelo Instituto de Arquitetura e Urbanismo de São Paulo (IAB-SP), entre $1^{\circ}$ de setembro e 12 de outubro de 1988, com discussões sobre o futuro da Arquitetura.

Naquela época, na gestão da FAU-Mackenzie dirigida pelo Arquiteto Hoover Américo Sampaio (Mackenzie, 1954), realizada no biênio 1984-1986, houve a preocupação de incentivar e promover uma harmonia entre docentes e discentes por meio de trabalhos e concursos estudantis, garantindo o bom funcionamento do Curso.

Tudo isso agregava, fomentava os ideais e motivava os alunos a questionar e a elaborar uma produção acadêmica arquitetônica bastante incomum. Destaca-se a riqueza das apresentações inspiradas nos arquitetos mineiros, como Éolo Maia e Sylvio de Podestá, ${ }^{3}$ que frequentavam a FAU-Mackenzie, a convite de alguns professores, e já influenciavam os alunos. O uso de cores e formas, o despojamento em relação à verdade do material, abrandando a ditadura do concreto armado, e a valorização da historicidade eram assuntos iminentes.

A consolidação da Avenida Engenheiro Luiz Carlos Berrini com os edifícios da construtora Bratke-Collet, projetados pelo Arquiteto Carlos Bratke, seguido pelo edifício de formas curvas revestidas de cerâmica de cor roxa, chamado "Terra Brasilis", dos Arquitetos Jorge Königsberger (Mackenzie, 1971) e Gianfranco Vannucchi (FAU-USP, 1975), reafirmavam o momento cheio de entusiasmo arquitetônico para a transformação da década de 1980. Esse entusiasmo se refletia nas apresentações das bancas de avaliação com as classes totalmente lotadas de colegas assistindo às apresentações do Trabalho Final de Graduação. Tal companheirismo não era cabotinismo, mas sim enfrentamento de posições por vezes opostas, que, sem dúvida, repercutiam no confronto de ideias de gerações que acontecia.

Um fato muito relevante desse movimento aconteceu em 1984, quando o Departamento de Projetos, sob a chefia do Professor Vasco de Mello, resolveu organizar com os alunos do quinto ano uma exposição no Museu da Imagem e do Som (MIS) com os melhores trabalhos finais de graduação. Essa exposição recebeu o nome "Próxima Paisagem", alusão feita à perspectiva de uma nova construção de cidade a ser realizada por jovens profissionais que ingressavam em outro momento de suas vidas. Esse evento ocorreu de 23 a 28 de abril de 1985 e a exposição foi um marco na história, porque deu origem a um concurso nacional de grande prestígio entre os alunos de último ano de graduação - o Ópera Prima. Também naquela ocasião foi prestada uma homenagem ao triste falecimento do Professor Joaquim Barreto (Mackenzie, 1967).

Dois anos depois, com os alunos da turma de 1986, outra exposição com o mesmo propósito aconteceu com os melhores trabalhos dos formandos da FAU-Mackenzie. Curiosamente, naquele ano foram acrescidos os melhores trabalhos dos estudantes da Faculdade de Arquitetura e Urbanismo da Universidade de São Paulo (FAU-USP).
Na página anterior:

MuBE - Museu Brasileiro da Escultura, São Paulo, 1987. Projeto do Arquiteto Paulo Mendes da Rocha (Mackenzie, 1954).

3. Arquitetos que representam uma produção arquitetônica e intelectual mineira, num momento em que se produziu um ambiente de renovação nas artes e na Arquitetura em Belo Horizonte, no final da década de 1970, em que se destaca a atuação de Éolo Maia e Sylvio Emrich de Podestá. 


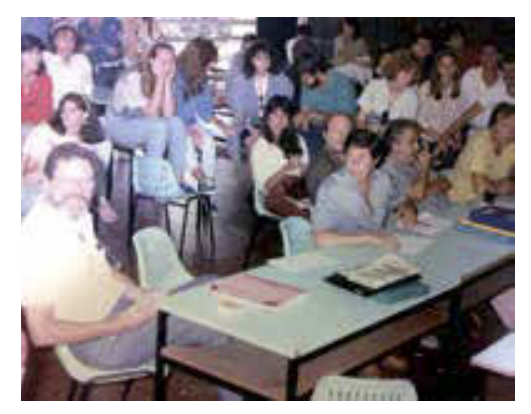

Banca de Trabalho Final de Graduação, anos 1980. Na foto, da esquerda para a direita, os Profs. Arquitetos José Carlos Ribeiro de Almeida (Zeca), Sami Bussab, Fabio Goldman, Tito Livio Frascino (atrás de Fabio) e Flavio Marcondes.

4. O Capítulo "A contribuição da FAU-

-Mackenzie nos concursos de Arquitetura e Urbanismo" apresenta um quadro que relaciona todos as premiações recebidas pelos estudantes da FAU-Mackenzie no Concurso Opera Prima.
Essa exposição ocorreu no Museu da Casa Brasileira, entre os dias 23 e 26 de abril de 1987, com o nome "O Tombo na Mola". Naquela oportunidade, a presença de dois debatedores prestigiou o evento, que selecionaram e indicaram os trabalhos mais destacados: o Arquiteto Paulo Mendes da Rocha (Mackenzie, 1954) e o jornalista Odon Pereira.

A partir de agosto de 1988, a Revista Projeto assumiu a organização desse importante evento, juntamente com o IAB - Nacional. Assim, outras escolas de Arquitetura passaram a participar da cerimônia apresentando sua melhor produção acadêmica. O evento ganhou prestígio e notoriedade no Brasil com o patrocínio de diversas marcas consagradas e passou a premiar os melhores trabalhos, transformando-se em um Concurso Nacional. Assim, podese dizer que a FAU-Mackenzie foi, de certa forma, o berço do Ópera Prima e, felizmente, tem sido premiada ou mencionada honrosamente na maioria das edições. ${ }^{4}$

Hoje, o concurso Ópera Prima encontra-se em sua $27^{\text {a }}$ edição e possui abrangência nacional. É inegável sua origem nas ideias dos professores do último ano da Graduação da FAU-Mackenzie, chefiados pelo professor Vasco de Mello e acompanhados dos professores Sami Bussab (Mackenzie, 1964), Tito Livio Frascino, José Carlos Ribeiro de Almeida (Mackenzie, 1964), Flávio Marcondes (Mackenzie, 1966), entre outros docentes do Departamento de Projeto.

\section{Mudanças curriculares e estruturais a partir de 1980 do Curso de Graduação em Arquitetura e Urbanismo}

Para compreender as mudanças no currículo e a estrutura da FAU-Mackenzie no decorrer do período de 1980 a 2000, é necessário o destaque de alguns elementos precursores. Em primeiro lugar, a Reforma Universitária de 1969 empreendida pelo Governo Federal trouxe repercussões à estrutura do Curso da FAU-Mackenzie, caracterizando um período de transformações.

De acordo com o Projeto Pedagógico de 2003:

No início da década de setenta, a Universidade Presbiteriana Mackenzie implantou a reforma universitária preconizada pelo Ministério da Educação e da Cultura, criando o Ciclo Básico composto de um conjunto de disciplinas de fundamentação no $1^{\circ}$ ano com Coordenação autônoma, independente da Faculdade de Arquitetura e Urbanismo restrita aos 4 anos subsequentes.

As disciplinas da Faculdade pertenciam a um único departamento, o Departamento de Arquitetura, posteriormente denominado Departamento de Pesquisas Arquitetônicas, uma vez que a denominação não deveria ser a mesma da Faculdade, pois a estrutura era departamental. 
O seu primeiro regimento foi aprovado em 1975 e se destacam os seguintes artigos:

Art. $2^{\circ}$ - O Departamento é vinculado à Faculdade de Arquitetura e Urbanismo e criado pela forma prevista no Regimento Geral; é responsável pelo ensino e pela pesquisa relativamente às disciplinas que Ihe estejam afetas, em nível de graduação, Pós-Graduação, de especialização, aperfeiçoamento, atualização ou extensão.

Art. $6^{\circ}$ - O Departamento é integrado por todos os professores titulares, professores adjuntos e professores assistentes em exercício efetivo de suas funções nas disciplinas abaixo listadas:

Teoria da Arquitetura I, II, III / Planejamento Al, All, AllI, AIV, Bl, BII, Cl, CII / Perspectiva A, B / História da Arquitetura I, II / Arquitetura de Exteriores / Arquitetura de Interiores / Arquitetura no Brasil / Projeto I, II, III, IV / Arquitetura / Urbanismo / Composição.

Art. 15 - O Departamento tem as seguintes sequências básicas:

Sequência de Projeto / Sequência de História / Sequência de Planejamento e Urbanismo / Sequência de Teoria da Arquitetura.

Art. 21 - Cada sequência é coordenada por um professor pertencente ao Departamento indicado pela Sequência e referendado pelo Departamento.

Pelo regimento observa-se que apenas um único Departamento da Faculdade possuía todas as atribuições da Faculdade porém limitado operacionalmente pela estrutura composta de apenas um professor Chefe e quatro Coordenadores de Sequência. (UNIVERSIDADE MACKENZIE, 2003, p. 25-26).

É importante salientar que, no período de 1980 a 2000, ocorreu a ampliação do número de vagas do Curso, de 100 alunos ingressantes por ano no final da década de 1970 para 200 ingressantes por semestre para os períodos matutino e vespertino, com a correspondente ampliação no corpo docente; além da passagem do Curso para periodicidade semestral em 1990. ${ }^{6}$ Em setembro de 1980, a Faculdade de Arquitetura oferecia os seguintes cursos e vagas para o vestibular de 1981: Arquitetura curso matutino, 100 vagas; Arquitetura curso noturno, 100 vagas, Comunicação Visual vespertino, 50 vagas; Desenho Industrial vespertino,

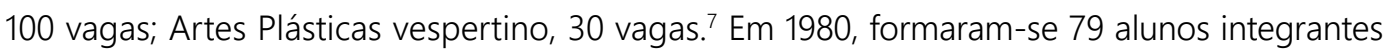
da primeira turma do curso noturno, que, a partir de 1989, transformou-se em curso vespertino, extinto em 1991 (UNIVERSIDADE MACKENZIE, 2003, p. 23).

A ampliação do corpo docente nos primeiros anos da década de 1990 foi resultante da melhoria da relação aluno-professor: em projeto, de 25 para 15 alunos por professor, ocorrida em 1994. Na ocasião, a direção da FAU-Mackenzie era conduzida pelo Prof. Roberto Righi.
5. Resta elucidar quais dessas disciplinas de Planejamento referem-se ao campo de conhecimento do planejamento urbano e regional e do urbanismo, distinguindo-se de outros aspectos do planejamento do ambiente construído.

6. A aprovação do regime semestral está registrada na Ata da Reunião do Cepe de 7 de fevereiro de 1990

7. Conforme Ata do Conselho Universitário (Consu) de $1^{\circ}$ de setembro de 1980. Note-se que em princípios da década de 1980 cria-se a Faculdade de Comunicações e Artes, com a migração de parte dos cursos da Faculdade de Arquitetura. 
Estádio do Canindé, Associação

Portuguesa de Desportos, São Paulo,

1969. Projeto do Arquiteto Hoover

Américo Sampaio (Mackenzie, 1954).

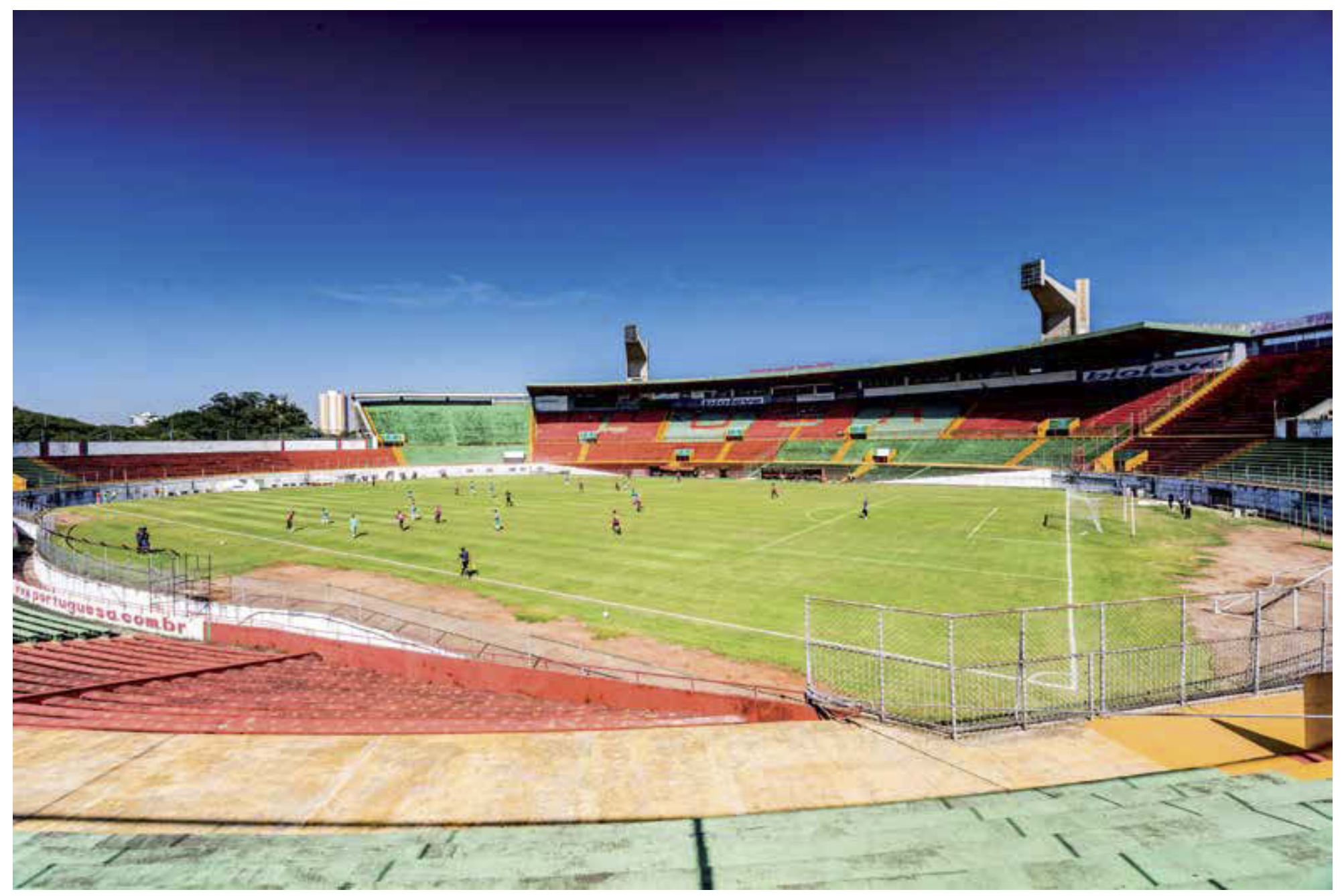


Para melhor compreender esse complexo período, cumpre aprofundar alguns aspectos. Em 1988, ocorreu a passagem do currículo do Curso anual para semestral. Justamente naquele final de década, aconteceram uma mudança disciplinar e uma redução da carga horária do Curso de Arquitetura e Urbanismo. Comparando os dados de 1988 e do período 1992-1994, é possível verificar uma perda de 480 horas/aula correspondentes a 96 horas/ano em média (UNIVERSIDADE MACKENZIE, 1994). A alteração quantitativa não foi tão grave quanto a qualitativa, consequência da redução mais acentuada nas disciplinas de formação, responsáveis pelo amadurecimento teórico e intelectual (VIANA, 1997).

No início da década de 1990, o Curso de Arquitetura já possuía 75 vagas matutinas e o mesmo número de vagas vespertinas, como atesta o vestibular do primeiro semestre de 1992, segundo a Ata no 25 do Conselho de Ensino e Pesquisa (Cepe) da UPM, de 07 de agosto de 1991, que foi mantido igual no segundo semestre de 1993, conforme a Ata n 35 do Cepe, de 7 de abril de 1993. Para o segundo semestre de 1995, o número de vagas passou para 100 no matutino e 75 no vespertino, conforme a Ata no 49 de 2 de agosto de 1995 do Cepe.

O currículo do Curso de Graduação semestral apresentado na Bienal de Arquitetura de 1994 (UNIVERSIDADE MACKENZIE, 1994), ocasião em que a FAU-Mackenzie foi reputada como uma das cinco faculdades pioneiras do Brasil, era composto por dez etapas, a saber:

$1^{a}$ etapa (9 disciplinas)

Metodologia Científica; Fundamentos de Física Geral; Matemática e Estatística; Projeto I; Expressão no Plano A 1 (Desenho); Representação Gráfica e Desenho Técnico aplicado à Arquitetura e Perspectiva I; Geometria Descritiva; Teoria da Arquitetura I; e Teoria da Informação; e Percepção I.

$2^{\text {a }}$ etapa (10 disciplinas)

Topografia l; Materiais e Técnicas de Construção l; Estudos de Problemas Brasileiros l; Projeto II; Resistência dos Materiais e Estabilidade das Construções l; Expressão no Plano A II (Desenho); Representação Gráfica e Desenho Técnico Aplicado à Arquitetura e Perspectiva II; Estética e História da Arte I; Evolução Urbana; Teoria da Arquitetura II; e Teoria da Informação e Percepção II.

$3^{\text {a }}$ etapa (11 disciplinas)

Materiais e Técnicas de Construção Il; Topografia II; Estudo de Problemas Brasileiros; Higiene da Habitação I; Projeto III; Expressão no Espaço (Maquete) I; Resistência dos Materiais e Estabilidade das Construções II; Planejamento Urbano I; Estética e História da Arte II; Teoria da Arquitetura III; e História da Arquitetura I. 
$4^{\mathrm{a}}$ etapa (10 disciplinas)

Sistemas de Construção I; Materiais e Técnicas de Construção III; Computação na Arquitetura I; Higiene da Habitação II; Projeto IV; Expressão no Espaço (Maquete) II; Expressão no Espaço (Plástica) I; Concreto Armado I; Planejamento Urbano II; Teoria da Arquitetura IV; e História da Arquitetura II.

$5^{\text {a }}$ etapa (11 disciplinas)

Materiais e Técnicas de Construção IV; Sistemas de Construção II; Instalações Hidráulicas I; Instalações Elétricas I; Projeto V; Expressão no Espaço (Plástica) II; Estruturas de Metal/Madeira I; Concreto Armado II; Planejamento Urbano III; Teoria da Arquitetura V; História da Arquitetura III; e Arquitetura no Brasil I.

$6^{\text {a }}$ etapa (11 disciplinas)

Materiais e Técnicas de Construção V; Instalações Hidráulicas II; Instalações Elétricas II; Projeto Vl; Arquitetura de Interiores I; Estrutura de Metal/Madeira II; Planejamento Urbano IV Paisagismo I; Teoria da Arquitetura VI; História da Arquitetura IV; e Arquitetura no Brasil II.

$7^{\text {a }}$ etapa (10 disciplinas)

Higiene e Saneamento I; Projeto VII; Arquitetura de Interiores II; Supervisão de Estágios I; Sistemas Estruturais I; Mecânica dos Solos I; Desenho Industrial na Arquitetura I; Paisagismo II; Planejamento Urbano V; e Estudos Socioeconômicos.

$8^{\text {a }}$ etapa (11 disciplinas)

Higiene e Saneamento II; Ecologia; Computação na Arquitetura II; Projeto VIII; Arquitetura de Interiores III; Supervisão de Estágios II; Sistemas Estruturais II; Mecânica dos Solos II; Desenho Industrial na Arquitetura II; Planejamento Urbano Vl; e Estudos Socioeconômicos.

$9^{a}$ etapa (4 disciplinas)

Projeto IX; Prática Profissional (Legislação) l; Organização e Administração I; Planejamento Urbano VII.

$10^{\mathrm{a}}$ etapa (4 disciplinas)

Projeto X; Prática Profissional (Legislação) Il; Organização e Administração Il; e Planejamento Urbano VIII. 
Quanto ao conteúdo das disciplinas, ocorreram mudanças progressivas e lentas ao longo dos anos desde a reforma universitária dos anos 1970, preconizada pelo Ministério da Educação e da Cultura (MEC). O ciclo básico com coordenação autônoma independente da Faculdade de Arquitetura e Urbanismo já não existia mais, mas a primeira e a segunda etapas, ainda em 1984, eram compostas de disciplinas de fundamentação do antigo primeiro ano.

O forte peso das disciplinas tecnológicas permaneceu em 1994, com a presença explícita da Escola de Engenharia em cerca de 30 disciplinas tradicionais e algumas poucas com conteúdos novos de informática e administração, ou seja, 1/3 do número de disciplinas ministradas. O acúmulo das disciplinas nos oito primeiros semestres deve ser compreendido a partir das exigências legais do MEC, que impôs aos cursos de Arquitetura e Urbanismo um tempo de adaptação para novas reformas que reservassem os últimos dois semestres para a realização exclusiva do Trabalho de Graduação Interdisciplinar (TGI), oficializado na FAU-Mackenzie a partir de meados de 1995. A saída inicial para essa exigência seria a diminuição drástica da carga horária. A participação do Departamento de Planejamento Urbano e Urbanismo foi muito relevante, bem como o de História e Teoria na requalificação e atualização dos conteúdos das disciplinas, que se libertaram das formas anuais de desenvolvimento e avaliação.

Na segunda metade dos anos 1990, as mudanças e modernizações curriculares se aceleraram, especialmente para cumprir as exigências legais da Portaria $n^{0} 1.770$ de 21 de dezembro de 1994, que fixou diretrizes curriculares e o conteúdo mínimo do Curso de Graduação em Arquitetura e Urbanismo, bem como da Lei de Diretrizes e Bases da Educação Nacional (LDB), ambas do MEC. Como consequência, surgem diversas iniciativas. Já em 1994 foi promovida a viagem de estudos e o curso de extensão universitária "Arquitetura Vivenciada: as Cidades Planejadas Palmas (Tocantins) e Brasília". Na Ata n 53 de 3 de abril de 1996 do Cepe é destacada a importância da informática para os arquitetos, propondo a criação de laboratório de informática e multimídia.

O crescimento do porte da FAU-Mackenzie, é expresso na Ata n 55 de 7 de agosto de 1996 do Cepe, que registrou 1.430 alunos matriculados, enquanto a Universidade contava com 20.973 discentes. Na mesma reunião, é aprovada a nova regulamentação do $\mathrm{TGl}^{8}$ por dois anos, já submetida ao Conselho Departamental da FAU-Mackenzie de 6 de agosto de 1995 e aprovada. Na sequência, é endossado na reunião no 57 do Cepe de 16 de outubro de 1996 o acompanhamento pelos docentes de TGI I e II e Projeto IX e X, que deveria ser feito pelo mesmo docente do início ao término do trabalho por vantagens pedagógicas.

Na Ata no 58 de 4 de dezembro de 1996 do Cepe é aprovada por unanimidade uma importante alteração curricular do Curso de Arquitetura e Urbanismo, já aprovada e encaminhada pelos Departamentos e o Conselho Departamental. Nela, são definidas medidas que mostram bem a situação, mas estão ainda muito distantes das que ocorrerão no final da década de 1990 e no início do século XXI. Elas envolviam: o aumento da carga horária de Projeto
8. À época, a coordenação do TGI foi atribuída ao Prof. Arquiteto Galba Osório. 
Mural no $1^{\circ}$ andar da Sede do

IAB-SP, São Paulo, 1967. Projeto do

Arquiteto Ubirajara Mota Lima Ribeiro

(Mackenzie, 1954).

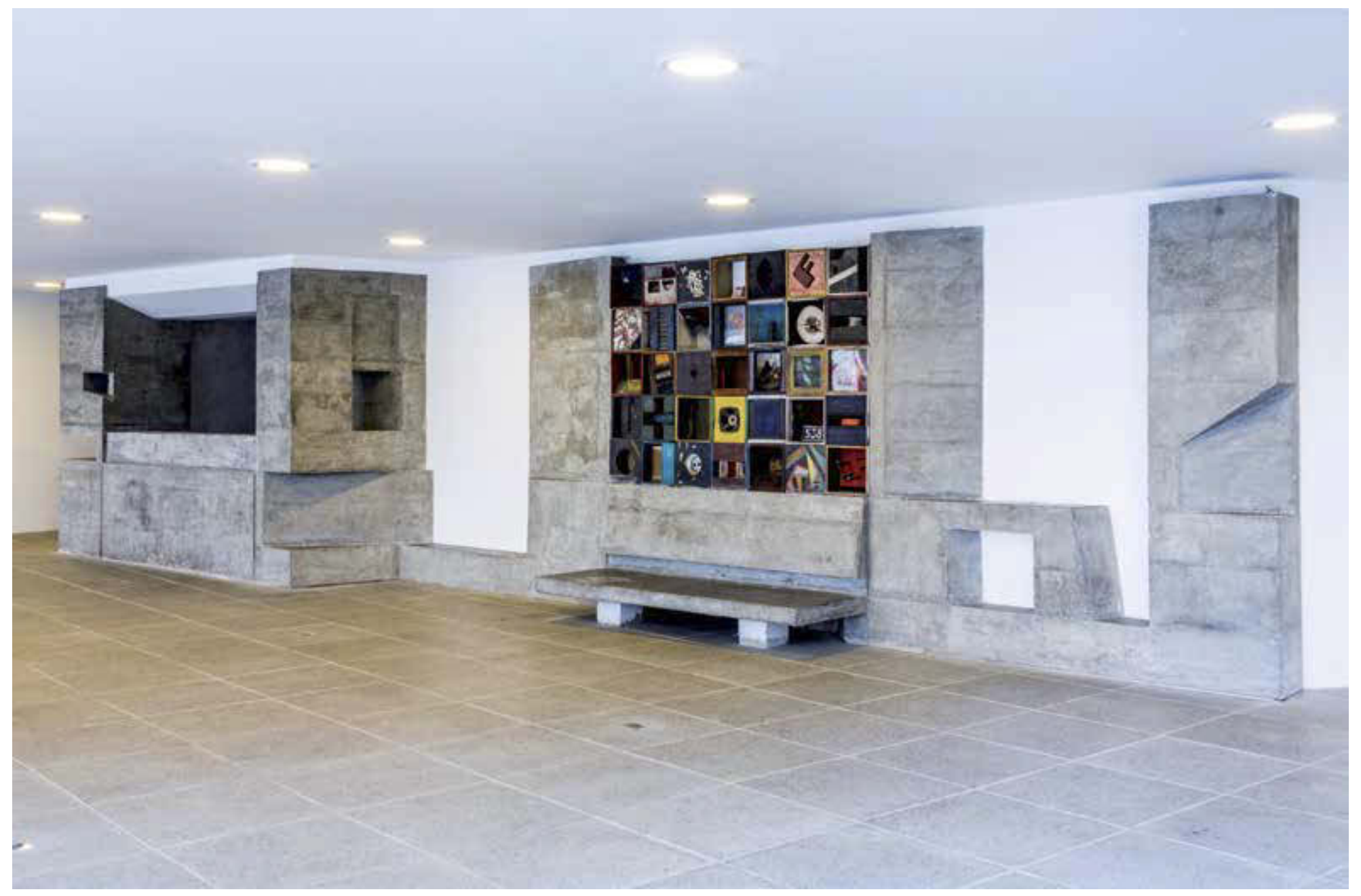


I de 6 para 8 horas semanais; a inclusão da Computação na Arquitetura III na $6^{\text {a }}$ etapa, com 3 aulas semanais; o incremento de uma aula prática por semana nas disciplinas de Teoria da Arquitetura I, II, III, IV, V e Vl; e a inclusão de História e Teoria das Técnicas Retrospectivas na sétima etapa, com duas aulas semanais.

Também foram aprovadas medidas voltadas à extensão universitária, que foram concebidas com a proposta do Escritório Modelo de Arquitetura (Poema) como forma de adequação à Portaria no 1.770 de 21 de dezembro de 1994, da Comissão de Ensino de Arquitetura e Urbanismo da Secretaria de Educação Superior (Sesu) do MEC, visando considerar o entorno social, econômico, mercadológico, que foi aprovado na reunião de 4 de junho de 1997 do Cepe.

No final do século XX, as mudanças se aceleraram. Entre outras providências, levaram à extinção dos Departamentos. Na reunião n 73 de 7 de abril de 1999 do Conselho de Ensino e Pesquisa (Cepe), foi relatada nova reformulação e atualização do currículo do Curso de Arquitetura e Urbanismo, assim expressa: a realocação de disciplinas entre disciplinas; a alteração da nomenclatura das disciplinas; alterações das emendas; exclusão de disciplinas da grade; inclusão de disciplinas. Toda essa profunda mudança era baseada no Projeto Pedagógico da Universidade, na Portaria n 1.770 e dos relatórios da Comissão de Avaliação e Diagnóstico da Estrutura Curricular e do Plano de Desenvolvimento Institucional (PDI) da FAU-Mackenzie.

Na reunião seguinte, a de $n^{\circ} 74$ de 2 de junho de 1999, foram discriminadas todas as mudanças a serem realizadas, as quais visavam a profunda alteração curricular, marcando a direção que foi impressa nos anos seguintes.

\section{Década de 1990 - Pós-Graduação em Arquitetura e Urbanismo da Universidade Presbiteriana Mackenzie: fundação e seus primeiros anos}

Na década de 1990, ocorreram grandes transformações na FAU-Mackenzie. Certamente, a mais profunda e duradoura foi a aprovação e autorização da instalação do Curso de Mestrado para o imediato funcionamento, pela Reunião $n^{\circ} 19$ de 8 de agosto de 1990 do Cepe. A proposta foi, em seguida, enviada para aprovação junto à Coordenação de Aperfeiçoamento de Pessoal de Nível Superior (Capes) ${ }^{9}$ (RIGHI, 1990).

Sua existência é atrelada à implantação da Pós-Graduação Stricto Sensu na UPM, que se demonstrava muito necessária. Na Reunião n 43 de 3 de agosto de 1994 do Cepe discutiu-se o fato de a UPM ser criticada pela imprensa escrita por sua posição pouco lisonjeira no levantamento divulgado "A Qualificação do Corpo Docente das Universidades Brasileiras". A UPM replicou que os dados se referiam a informações coletadas entre 1984 e 1990, época em que os resultados da Pós-Graduação ainda não existiam, mostrando a urgência e a expectativa colocada na Pós-Graduação da Universidade.
9. O Prof. Dr. Roberto Righi esteve à frente da coordenação da Pós-Graduação nos primeiros oito anos de funcionamento. Um estudo mais aprofundado desta atuação é apresentado no capítulo dedicado à Pós-Graduação em Arquitetura e Urbanismo da UPM. 
10. No Capítulo "Mestrado e Doutorado em Arquitetura e Urbanismo:uma história de sucesso" será relatada detalhadamente a história da Pós- Graduação Stricto Sensu da FAU-Mackenzie.

11. Conforme o Projeto Pedagógico de 2003: "Em 1979 a faculdade passou a se chamar 'Faculdade de Arquitetura e Urbanismo', traduzindo a ampliação do campo profissional e acadêmico. Em 1980 formam-se 79 alunos integrantes da $1^{\text {a }}$ turma do curso noturno, que a partir de 1989 transformou-se em curso vespertino. Em 1990 o curso foi reestruturado, passando a ser organizado de forma semestral" (UNIVERSIDADE MACKENZIE, 2003, p. 23). Há aqui uma sequência cronológica que necessita maior elucidação, pois mais adiante afirmase que a estrutura semestral passou vigorar a partir de 1990.

12. As disciplinas técnicas tradicionalmente ligadas às engenharias eram de responsabilidade do Departamento de Engenharia Civil, que não se vinculava à Faculdade de Arquitetura, seja em seus aspectos pedagógicos, seja em seus aspectos administrativos. O Departamento de Técnicas de Arquitetura foi criado e instalado apenas em novembro de 1998 por meio do Ato da Reitoria $\mathrm{n}^{\circ} 13$ de 25 de novembro de 1998, como se vê adiante (BRASIL, 2012, p. 31)
O prenúncio da mudança na UPM como resultado do avanço da Pós-Graduação já era indicado no artigo de Darcy Ribeiro no Jornal do Brasil, de 26 de julho de 1993, "Darcy defende o domínio do saber moderno". Nele, o saudoso autor mencionava a UPM como exemplo de instituição séria e competente .

A decisão favorável ao reconhecimento foi muito importante para a história da Pós-Graduação em Arquitetura e Urbanismo da UPM, pois agregou a ela mais de dez anos de existência. Foi somente em 22 de setembro de 2000 que a Universidade teve sua proposta mais recente avaliada e recomendada pela Capes com conceito três para a implementação do Mestrado; no primeiro semestre de 2006, o Curso de Doutorado foi também recomendado, fato que levou a continuidade que levou à continuidade e a decisão retroativa tomada em 2012, quando os diplomas expedidos na primeira fase são reconhecidos (BRASIL, 2012). ${ }^{10}$

\section{Criação do Departamento de Planejamento Urbano e Urbanismo}

Grandes mudanças ocorreram nas décadas de 1980 e 1990 na FAU-Mackenzie. Em 1979, a faculdade passou a se chamar Faculdade de Arquitetura e Urbanismo, traduzindo a ampliação do campo profissional e acadêmico. O Departamento de Planejamento e Urbanismo ${ }^{11}$ foi criado no início da década de 1980, por iniciativa do Prof. Jairo M. Ludmer, com a participação de um pequeno grupo de professores, entre os quais se destacavam Celson Ferrari, Roberto Righi e Walter Vicente Silva. Esse processo foi devido a um desdobramento do Departamento de Pesquisas Arquitetônicas, cujo núcleo principal resultou no Departamento de Projetos Arquitetônicos. Nessa reforma, permaneceu inalterado o Departamento de História e Teoria da Arquitetura (RIGHI, 1990, p. 27).12

A extinção do ciclo básico ocorreu em 1988, sendo o primeiro ano de estudos reincorporado à estrutura da FAU-Mackenzie, implantando-se a sequência de disciplinas de Projeto de I a X vinculadas ao Departamento de Projeto. No período de reestruturação do Curso - que passa da periodicidade anual das disciplinas para a semestral -, ocorre o desdobramento das disciplinas anuais da sequência de Planejamento Urbano em oito disciplinas semestrais, iniciando-se no primeiro semestre do segundo ano (ou seja, no $3^{\circ}$ semestre) e terminando no último semestre do Curso ( $10^{\circ}$ semestre). A essa sequência são agregadas as disciplinas de Paisagismo I e II em substituição de Arquitetura de Exteriores na constituição do Departamento de Planejamento e Urbanismo.

Mudanças foram realizadas sucessivamente, com alterações paulatinas e sucessivas nos conteúdos programáticos das disciplinas. As modificações eram encaminhadas em reuniões de departamento com a participação dos professores das disciplinas. Ocorreu a introdução de novas questões e problemáticas, como os Estudos e os Relatórios de Impacto Ambiental. Em 1999, foram realizados dois encontros para o aprofundamento 
pedagógico no âmbito do Departamento de Planejamento e Urbanismo: o Programa de Aprofundamento Pedagógico, iniciado em 26 de março, e o I Encontro de Professores do Departamento de Planejamento e Urbanismo, ocorrido em 20 de maio, com o objetivo de discutir conteúdos e processos de aprendizagem relativos ao campo de conhecimento e atuação em Planejamento e Urbanismo.

O desenvolvimento de pesquisas vinculadas à constituição do Fundo Mackenzie de Pesquisa (MackPesquisa), bem como dos grupos de pesquisa e a consolidação da Pós-Graduação, com a regularização do Mestrado e finalmente Doutorado, em 2006, revestem-se de grande importância para a atualização temática e profissional da formação em Planejamento e Urbanismo.

A criação e a implementação do Trabalho Final de Graduação (TFG), em 2001, preenchendo o quinto e o último anos de formação com um conjunto de quatro atividades distintas em seu interior e a exigência de completar todas as demais disciplinas do Curso nos quatro anos iniciais ocorrem em processo concomitante ao deslocamento do início da sequência das oito disciplinas de Planejamento Urbano, do primeiro ao oitavo semestre, com a disciplina de Evolução Urbana permanecendo no segundo semestre. Assim, a sequência de disciplinas de Planejamento Urbano de I a VIII, em correspondência aos semestres respectivos do Curso, e a disciplina de Evolução Urbana (optativa) localizada no segundo semestre, até ali vinculadas ao Departamento de Planejamento e Urbanismo, passaram a vincular-se ao Eixo Temático de Urbanismo (UNIVERSIDADE MACKENZIE, 2008, p. 2).

\section{A difícil gênese e a breve existência do Departamento de Tecnologia}

A FAU-Mackenzie sempre destacou-se em atividades que priorizam as técnicas de construção. Fato historicamente fundamentado na própria criação do Curso de Arquitetura, que se deu junto à Escola de Engenharia, em 1917, associada às suas bases protestantes, que priorizavam uma formação mais prática. Também com a intenção de reafirmar a posição de destaque da FAU-Mackenzie no mercado nacional e internacional, além de cumprir com as exigências legais contidas tanto na Portaria no 1.770 quanto na Lei de Diretrizes e Bases do MEC, tornou-se necessária a criação do Departamento de Técnicas de Arquitetura.

O primeiro registro encontrado da tentativa de criação do Departamento de Tecnologia na FAU-Mackenzie foi a Ata no 48 de 7 de junho de 1995 do Cepe. Porém, a matéria foi retirada de pauta sem explicações. Nova tentativa ocorreu na reunião no 56 de 21 de agosto de 1996 do Cepe, que levou à aprovação imprópria e errônea do Departamento de Tecnologia e Construção Civil vinculado à Faculdade de Tecnologia, conforme denúncia do Professor Walter Saraiva Kneese, em Ofício de 2 de setembro de 1996 (UNIVERSIDADE MACKENZIE, 1996). Novamente, em Ofício de 9 de outubro de 1997, o Professor Walter Saraiva Kneese entre outros, solicitou ao Magnífico Reitor reencaminhamento do processo de criação do Departamento de 


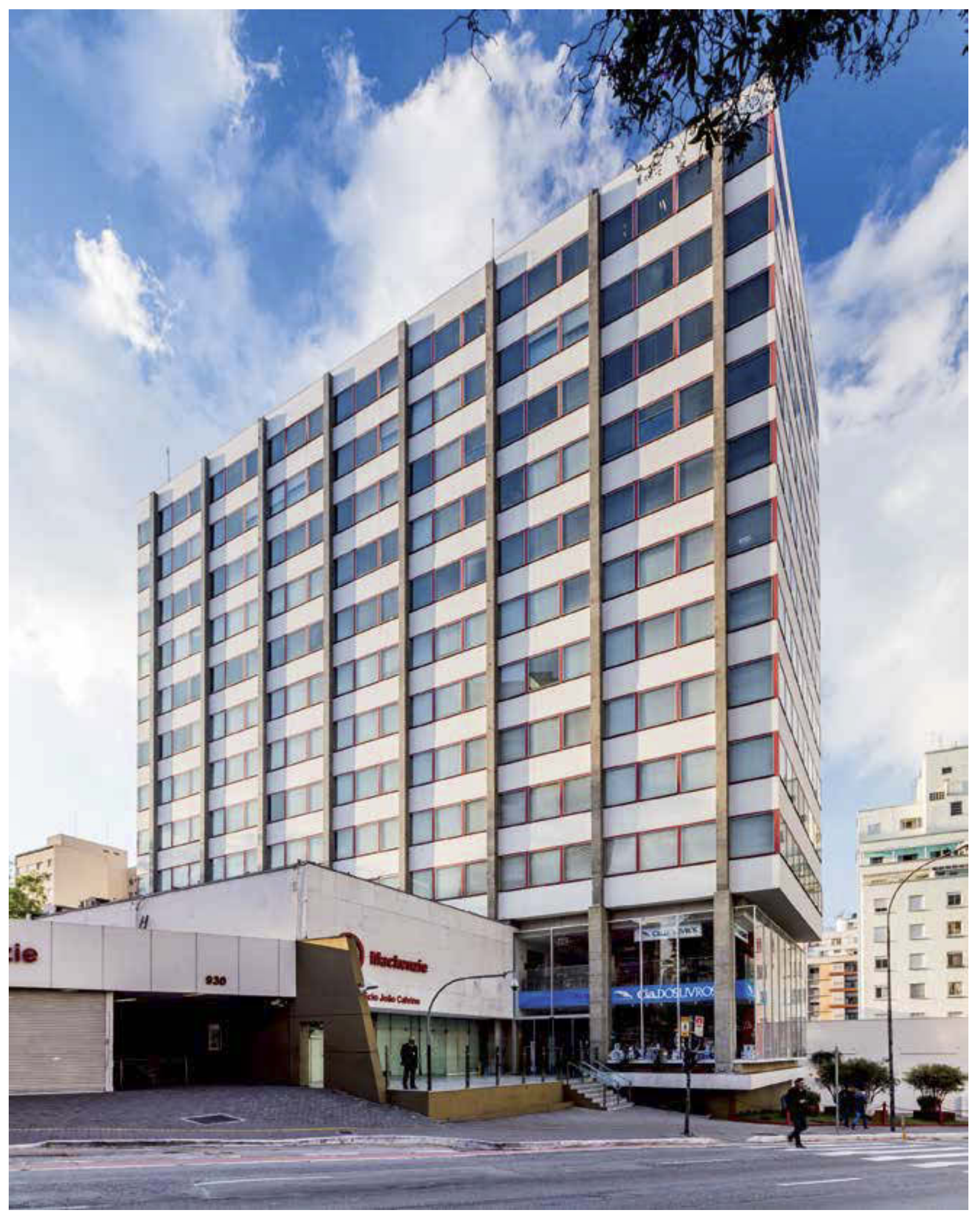


Tecnologia da Arquitetura e Urbanismo ao Cepe (UNIVERSIDADE MACKENZIE, 1997). Outra vez, em 2 de março de 1998, o Diretor por ofício agradece o entendimento da solicitação, além da análise e parecer do Vice-Reitor Prof. Marcel Mendes. Anuncia também que a proposta estava em condições de retornar ao Cepe ${ }^{13}$ (UNIVERSIDADE MACKENZIE, 1998).

Um dos objetivos da criação do Departamento de Técnicas de Arquitetura da FAU-Mackenzie era adequar as disciplinas da área técnica lecionadas na Faculdade aos anseios do Projeto Pedagógico e às novas legislações de ensino de Arquitetura. Assim, coordenava-se horizontal e verticalmente, de acordo com as especificidades de cada uma delas e em consonância com os interesses dos departamentos de Projetos Arquitetônicos, Planejamento e Urbanismo, e de Teoria e História.

Essa mudança visava fornecer aos futuros profissionais os conhecimentos e as habilidades típicas da profissão de Arquiteto e Urbanista, levando também em consideração o perfil desejado para o egresso da FAU-Mackenzie. As disciplinas do Departamento de Técnicas de Arquitetura foram estruturadas em três grupos: Tecnologia da Construção, Conforto Ambiental e Sistemas Estruturais. Houve ainda a modernização dos conteúdos programáticos e metodologias adotadas em sala de aula, para a integração horizontal e vertical da grade curricular dos demais departamentos, em consonância com o Projeto Pedagógico. As disciplinas correspondentes a cada grupo são apresentadas no quadro 1, a seguir.

Ressalta-se que outro objetivo do Departamento de Técnicas de Arquitetura era a criação do canteiro experimental. Sua intenção era colocar em prática a teoria desenvolvida em sala de aula, permitindo ao aluno contato com materiais e técnicas de construção. O canteiro experimental só foi inaugurado em 2014.

Os resultados obtidos com a criação do Departamento de Técnicas de Arquitetura foram positivos por diversas razões, por exemplo: alcançou-se autonomia em relação ao Curso de Engenharia Civil; a estrutura adotada para o novo modelo proporcionou maior integração entre as diversas disciplinas do recém-criado departamento, bem como destas com os demais departamentos da FAU-Mackenzie; decisões que afetavam o departamento e sua estrutura eram tomadas na própria unidade, visto que o departamento estava vinculado a ela; aumento do número de pesquisas desenvolvidas junto ao Curso de Pós-Graduação; aumento do número de professores doutores em áreas técnicas e afins, envolvidos com disciplinas e pesquisas relacionadas ao Departamento de Técnicas de Arquitetura, entre outras.

A existência do Departamento de Técnicas de Arquitetura foi, no entanto, curta, pois todos os Departamentos da FAU-Mackenzie foram extintos pela Comissão de Reestruturação Curricular, instituída pelo Reitor Cláudio Lembo, no início do século XXI.
Na página anterior:

Edifício João Calvino (antiga sede da Cia Nestlé, 1961), onde funcionam hoje salas de aula da Pós-Graduação (PPGAU FAU-Mackenzie), a Reitoria, Pró-Reitorias e outras instâncias administrativas acadêmicas da Universidade, em São Paulo. Projeto dos Arquitetos Alberto Botti (Mackenzie, 1954) e Marc Rubin (Mackenzie, 1955).

13. Finalmente, em Portaria da Reitoria $\mathrm{n}^{\circ} 71$ de 27 de novembro de 2001 foi designada a Profa. Eleana Patta Flain para exercer pro-tempore o cargo de Chefe do Departamento de Técnicas da Arquitetura, vinculado à FAU-Mackenzie. 
Quadro 1 - Conjuntos de disciplinas do Departamento de Técnicas de Arquitetura, com sua denominação anterior e nova

\begin{tabular}{|c|c|c|}
\hline Grupo & Denominação anterior & Denominação nova \\
\hline \multirow{11}{*}{ 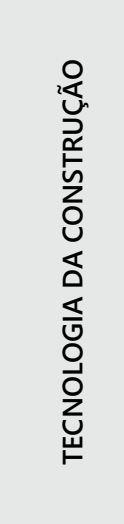 } & Topografia I & Topografia para Arquitetos I \\
\hline & Topografia II & Topografia para Arquitetos II \\
\hline & Materiais e Técnicas de Construção I & Materiais e Técnicas de Construção I \\
\hline & Materiais e Técnicas de Construção II & Materiais e Técnicas de Construção ॥ \\
\hline & Materiais e Técnicas de Construção III & Materiais e Técnicas de Construção III \\
\hline & Materiais e Técnicas de Construção IV & Materiais e Técnicas de Construção IV \\
\hline & Materiais e Técnicas de Construção V & Materiais e Técnicas de Construção V \\
\hline & Higiene e Saneamento I & Saneamento Ambiental I \\
\hline & Higiene e Saneamento II & Saneamento Ambiental II \\
\hline & Sistemas de Construções I & Sistemas Construtivos Aplicados à Arquitetura I \\
\hline & Sistemas de Construções II & Sistemas Construtivos Aplicados à Arquitetura II \\
\hline \multirow{3}{*}{ 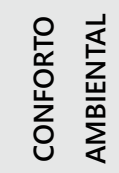 } & Instalações Elétricas | & Eletricidade Predial \\
\hline & Instalações Elétricas II & Luminotécnica \\
\hline & Instalações Hidráulicas & Instalações Hidráulicas e Sanitárias \\
\hline \multirow{9}{*}{ 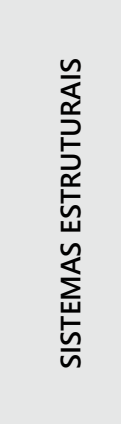 } & Resistência dos Materiais & Elementos das Estruturas \\
\hline & Estabilidade das Construções & Teoria e Técnicas das Estruturas Correntes \\
\hline & Concreto Armado I & Concreto Armado Aplicado à Arquitetura I \\
\hline & Concreto Armado II & Concreto Armado Aplicado à Arquitetura II \\
\hline & Estruturas Metálicas e de Madeira & Estruturas Arquitetônicas de Metal e de Madeira \\
\hline & Mecânica dos Solos I & Fundamentos de Geotecnia I \\
\hline & Mecânica dos Solos II & Fundamentos de Geotecnia II \\
\hline & Sistemas Estruturais I & Sistemas Estruturais Aplicados à Arquitetura I \\
\hline & Sistemas Estruturais II & Sistemas Estruturais Aplicados à Arquitetura II \\
\hline
\end{tabular}

Fonte: Acervo de Eleana Patta Flain

\section{As novas qualificações do corpo docente}

É importante assinalar a diversidade de formação e a crescente qualificação do corpo docente que progressivamente ocorreu, em especial nas décadas de 1980 e 1990. Esse importante processo de mudança se deu com a formação e a contratação de professores mestrandos e doutorandos. Essa nova dinâmica trouxe novas temáticas para a Graduação e a Pós-Graduação. Assim, junto com a qualificação dos professores existentes, houve contratação de novos docentes, integrando-os em uma complexa sinergia, com efeitos riquíssimos para a transformação qualitativa do capital intelectual da FAU-Mackenzie. 
As estratégias de aperfeiçoamento contemplaram as mais diversas modalidades. Alguns professores desenvolveram importantes estudos na área de Urbanismo e do Planejamento Urbano, os quais eram provenientes da prática profissional ou da especialização acadêmica em Planejamento Urbano e Urbanismo em órgãos públicos e privados. ${ }^{14}$ Também na década de 1990 passaram a lecionar na FAU-Mackenzie diversos arquitetos que participaram de projetos urbanos e de concursos urbanísticos de relevo. ${ }^{15}$ Em outro grupo, estavam os jovens Arquitetos que desenvolveram estudos urbanísticos em nível de Pós-Graduação. ${ }^{16}$

É importante destacar que muitos desses professores participaram de disciplinas da sequência de Planejamento e Urbanismo, devido à expansão e à necessidade de atualização teórica e profissional. Também é importante acentuar o retorno, no sentido do aumento da diversidade de pensamento e como resgate do período repressivo, de alguns professores que foram convidados a voltar. ${ }^{17}$

A necessidade da crescente qualificação correspondeu também ao início do Curso de Pós-Graduação em Arquitetura e Urbanismo ocorrido em 1990 e o seu desenvolvimento, já comentado. ${ }^{18}$ Nela, foram introduzidos temas inovadores na área do Planejamento Urbano e Urbanismo, e Desenho Urbano. Nesse contexto estimulante, deram-se conjuntos de cursos, palestras e aulas viabilizadas pela contratação de professores que introduziram novas temáticas.

Essas novas abordagens envolviam a requalificação de áreas centrais, Desenho Urbano e operações urbanas, e professores e disciplinas no Curso de Pós-Graduação. ${ }^{19}$ Partindo do trabalho do Professor Hans-Joachim Aminde, de Stuttgart (estudos de praças e novos espaços urbanos), em 1993 e 1994, foi estabelecido um intercâmbio com o Institut für Bauten Universität Stuttgart, para a realização de um workshop cujo tema era São Paulo - Anhangabaú. O laboratório durou dois anos, com a vinda de estudantes alemães, que trabalharam lado a lado com professores e estudantes da FAU-Mackenzie, permitindo a elaboração de projetos alemães e brasileiros. No lado alemão, as propostas eram mais fantasiosas, enquanto no brasileiro se desenvolveram técnicas inovadoras de desenho urbano contextualizado, de grande influência ulterior sobre as disciplinas de Planejamento Urbano e Urbanismo da Faculdade.

Nesse contexto, deve ser lembrada a participação de professores em diversos concursos e consultorias de projetos urbanos, por exemplo, no Concurso para um novo centro de São Paulo, 1996-1997:20 o Projeto Eixo Tamanduathey, ${ }_{1}^{21}$ em 1998.

\section{Considerações finais}

As transformações arquitetônicas e urbanísticas das décadas de 1980 e 1990 estão relacionadas às condições econômicas e sociais, por meio das novas exigências ditadas pela globalização e relação diferenciada entre o profissional e o mercado, exigindo projetos e obras de elevada qualidade formal, distinção estética e excelência tecnológica.
14. Podem-se enumerar nesta categoria os professores: Nadia Somekh, Silvana Zioni, Marcelo Bernardini, Angélica Tanus Benatti Alvim, Denise Antonucci, Luiz Ackel e outros.

15. José Magalhães, Roberto Righi, Héctor Vigliecca, José Paulo de Bem, Bruno Padovano e outros.

16. Angelica Tanus Benatti Alvim, Carlos Leite, Mario Figueiroa e outros.

17. Como: José Magalhães, Telésforo Giorgio Cristófani e outros.

18. Coordenado pelo Prof. Dr. Roberto Righi desde sua fundação até 1996

19. Como: Vicente Del Rio e Bruno Padovano (Desenho Urbano), Paulo Bruna (Projetos Urbanos Contemporâneos); Hans Joachim Aminde, de Stutgart (estudos de praças e novos espaços urbanos)

20. Ganho pela equipe do Prof. Dr. Roberto Righi e dos Profs. José Paulo de Bem, José de Magalhães Jr. (Mackenzie, 1963), que contou com a colaboração da equipe do urbanista espanhol Eduardo Leira.

21. Que contou também com a participação dos Profs. Dr. Roberto Righi e José Paulo de Bem, na equipe do Arquiteto francês Cristian de Portzamparc e do Prof. José Magalhães., na equipe do espanhol Eduardo Leira. 


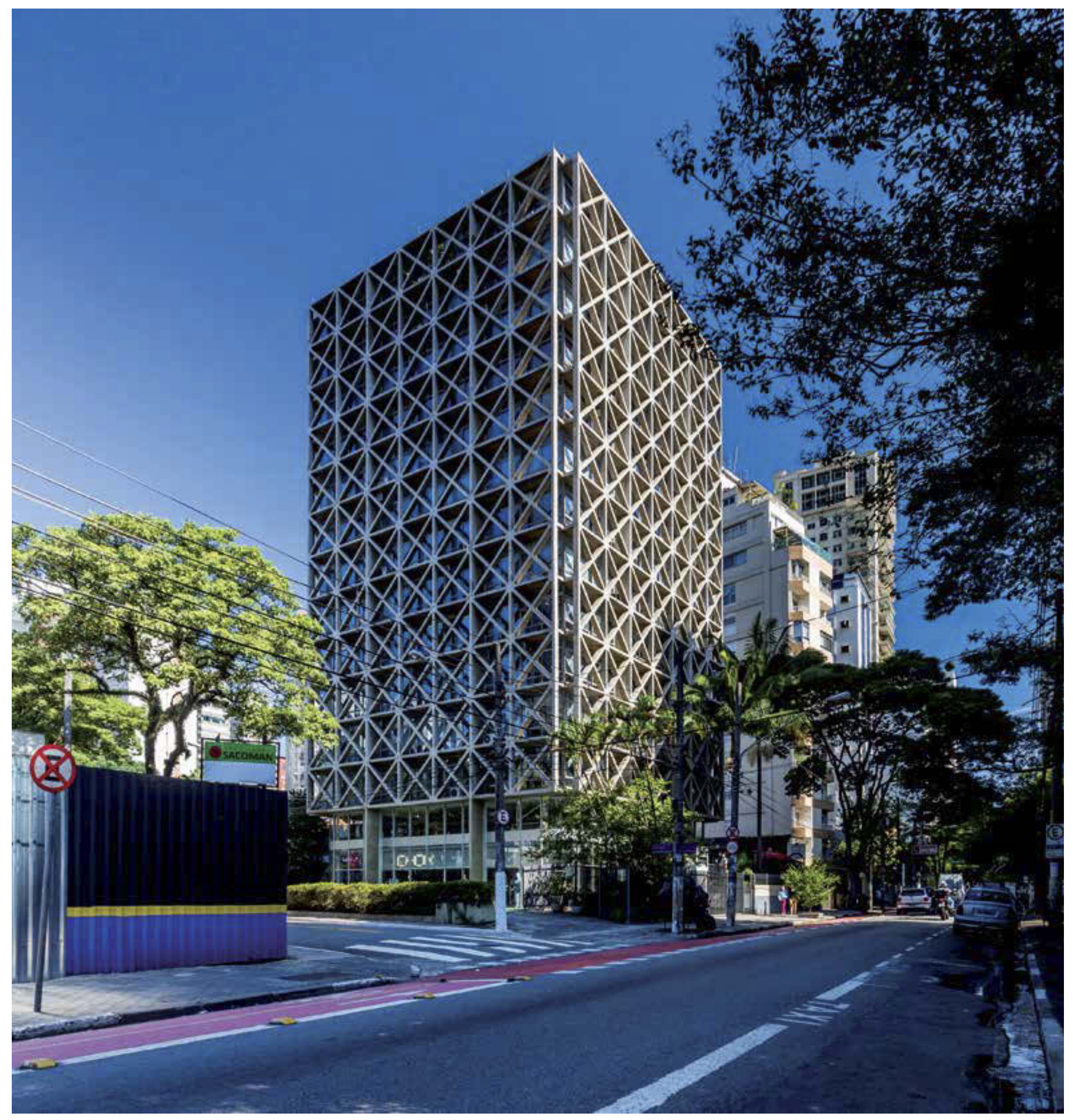


No cenário urbano, destaca-se a estética formal e a técnica dos projetos de Arquitetura como um instrumento de competição empresarial. Esse fenômeno aprofundou-se em São Paulo, nas décadas de 1980 e 1990, associado ao processo de expansão imobiliária e à intensa verticalização.

As discussões que buscavam consolidar a transformação do paradigma modernista para o pós-modernismo já se esboçavam nas décadas anteriores, mas adquiriram força e profundidade nos anos 1980, devido à abertura política. Houve o desenvolvimento de importantes mudanças no currículo e na estrutura da FAU-Mackenzie no decorrer dos anos de 1980 a 2000, que buscavam estar sincrônicos com a Arquitetura e Urbanismo internacionais no contexto da sociedade brasileira.

Em 1979, houve a mudança para a Faculdade de Arquitetura e Urbanismo, que traduziu o novo comprometimento e a ampliação do campo profissional e acadêmico. Pouco tempo depois, por iniciativa de professores, criou-se o Departamento de Planejamento Urbano e Urbanismo, qualificando e consolidando essa intenção de melhoria da formação profissional dos alunos. A criação da Pós-Graduação em Arquitetura e Urbanismo em 1990 certamente foi a resposta mais intensa e persistente para esse clamor de atualização e inserção social. Infelizmente, o resultado do reconhecimento oficial tardou 22 anos, mas fez justiça ao empenho de todos que participaram dessa empreitada, que incluiu o Programa de Pós- Graduação em Arquitetura e Urbanismo da UPM entre os primeiros do país, fazendo repetir o pioneirismo do Curso de Graduação, que, neste ano de 2017, completa 100 anos de existência.

Apesar de sua breve existência, o Departamento de Técnicas de Arquitetura permitiu a autonomia da Escola de Engenharia na orientação mais adequada e a integração de diversas disciplinas associadas a esse novo departamento com outras inseridas em departamentos já existentes na FAU-Mackenzie.

Finalmente, a diferenciação e a crescente qualificação do corpo docente ocorreram progressivamente nas décadas de 1980 e 1990. Houve um processo de mudança com a formação e a contratação de professores, mestrandos e doutorandos, estimulado pela afirmação da pós-graduação nascente na segunda década. Essa nova dinâmica acadêmica trouxe novas temáticas para a graduação e principalmente para a Pós-Graduação. Também ocorreu junto com o desenvolvimento dos professores existentes a contratação de novos docentes uma complexa sinergia, riquíssima na modificação qualitativa do capital intelectual da FAU-Mackenzie.
Na página anterior:

Edifício Acal, São Paulo, 1974. Projeto dos Arquitetos Pedro Paulo de Melo Saraiva (Mackenzie, 1955), Sergio Ficher (FAU-USP, 1972) e Henrique Cambiaghi Filho (FAU-USP, 1973). 


\section{Referências}

BRASIL. Ministério da Educação, Conselho Nacional de Educação. Parecer Homologado, Despacho do Ministro. Diário Oficial da União, Brasília, DF, 4 abr. 2012. Seção 1, p. 29.

CÂMARA MUNICIPAL de São Paulo. Seção de Protocolo. Moção n 255 de 25 de ago. 1983 do Vereador Lauro Ferraz e outros em solidariedade com os estudantes da Universidade Mackenzie na luta pela democratização de sua universidade. 1983. Disponível em: <www2. camara.sep.gov.br/projetos/1983/00/00.OC.NA.00000CNAY.pdf>. Acesso em: 11 mar. 2017.

CURSOS FORMAM profissionais bem diferentes. Folha de S.Paulo, 2 out. 1997. Faculdades. Arquitetura e Urbanismo.

INSTITUT für Bauten Universität Stuttgart. Relatório do intercâmbio com o Institut für Bauten Universität Stuttgart Workshop tendo como tema: São Paulo - Anhangabaú. Stuttgart: IFBUS, 1994.

PROMON Engenharia. Concurso Nacional de Ideias para um Novo Centro da Cidade de São Paulo. São Paulo: Promon, 1997.

RIGHI, R. Arquitetura moderna e contemporânea brasileira: exercício profissional e ensino. Dynamis, FURB, v. 8, n. 32, jul./set., p. 60-65, 2000.

Pós-Graduação da FAU-Mackenzie. Nascimento em 9 de agosto de 1990. Drops, 057.05, ano 12, jun. 2012. Disponível em: <http://www.vitruvius.com.br/revistas/read/ drops/12.057/4378>. Acesso em: 7 jun. 2017.

Uma ideia que deu certo. Faculdade de Arquitetura e Urbanismo, 1947-1997. Universidade Mackenzie. Organização Carlos Egídio Alonso. São Paulo: Universidade Mackenzie, 1997.

RIGHI, R.; SIMÕES JR, J. G.; ABASCAL, E.; KATO, V.; CASTRO, L. G. R. de. Análise crítica da arquitetura paulista nas décadas de 1980 e 1990 - Relatório Semestral da Pesquisa. J. G. L. G. São Paulo: Fundo Mackenzie de Pesquisa, 2002.

RIGHI, R.; BENATTI, A. A. T.; BRUNA, G. C.; SIMÕES, Jr., J. G.; CASTRO, L. G. R. de. Avaliação comparativa da formação e atuação profissional do urbanista no Brasil e em Portugal Relatório Final da Pesquisa. J. G. L. G. São Paulo: Fundo Mackenzie de Pesquisa, 2011.

RIGHI, R.; CASTRO, L. G. R. de. A edificação como produto imobiliário no desenvolvimento da arquitetura contemporânea em São Paulo. In: DUARTE, C. R. (Org.). O lugar do projeto no ensino e na pesquisa em arquitetura e urbanismo. (Contra capa). Rio de Janeiro: Proarq UFRJ, 2007. 
UNIVERSIDADE MACKENZIE. FAU - Ofício 02/09/1996, Prof. Walter Saraiva Kneese. São Paulo: UPM, 1996.

FAU - Ofício 09/10/1997, Prof. Walter Saraiva Kneese. São Paulo: UPM, 1997.

FAU - Ofício 02/03/1998, Prof. Walter Saraiva Kneese. São Paulo: UPM, 1998.

Painéis de apresentação da FAU-Mack na Bienal de Arquitetura de 1994. Pesquisas, programação visual e textos: Carlos Eduardo T. Packer, Celso Lomonte Minozzi, Galba Ozório, Marcia Serra Ribeiro Viana, Maria Teresa S. e Breia, Monica Junqueira Camargo e Roberto Righi. São Paulo: Laboratório D-76, 1994.

Projeto memória UPM. Entrevista do Prof. Hoover Américo Sampaio, nov. 1997a.

Projeto memória UPM. Entrevista do Prof. Walter Saraiva Kneese, nov. 1997b.

Projeto Pedagógico. São Paulo: UPM, 2003.

Projeto Pedagógico. São Paulo: UPM, 2008.

Secretaria Geral. Conselho Universitário. Livro de Atas de 1979 a 1980. No 147 a No 167.

São Paulo: UPM, 1998a.

Secretaria Geral. Conselho Universitário. Livro de Atas de 1980 a 1981. № 168 a No 191.

São Paulo: UPM, 1998b.

Secretaria Geral. Conselho Universitário. Livro de Atas de 1982 a 1984. № 192 a No 234. São Paulo: UPM, 1998c.

Secretaria Geral. Conselho Universitário. Livro de Atas de 1985 a 1986. № 235 a No 253. São Paulo: UPM, 1998d.

Secretaria Geral. Conselho Universitário. Livro de Atas de 1986 a 1987. № 254 a No 271. São Paulo: UPM, 1998e.

Secretaria Geral. Conselho Universitário. Livro de Atas de 1988 a 1990. № 272 a No 291. São Paulo: UPM, 1998 .

Secretaria Geral. Conselho de Ensino, Pesquisa e Extensão. Livro de Atas de 1987 a 1990. No 01 a No 21. São Paulo: UPM, 1998g.

Secretaria Geral. Conselho de Ensino, Pesquisa e Extensão. Livro de Atas de 1991 a 1993. No 22 a No 39. São Paulo: UPM, 1998h.

. Secretaria Geral. Conselho de Ensino, Pesquisa e Extensão. Livro de Atas de 1994 a 1998. No 40 a No 58. São Paulo: UPM, 1998i. 
Edifício Albatroz, São Paulo, 1960 Projeto do Arquiteto João Kon (Mackenzie, 1955).

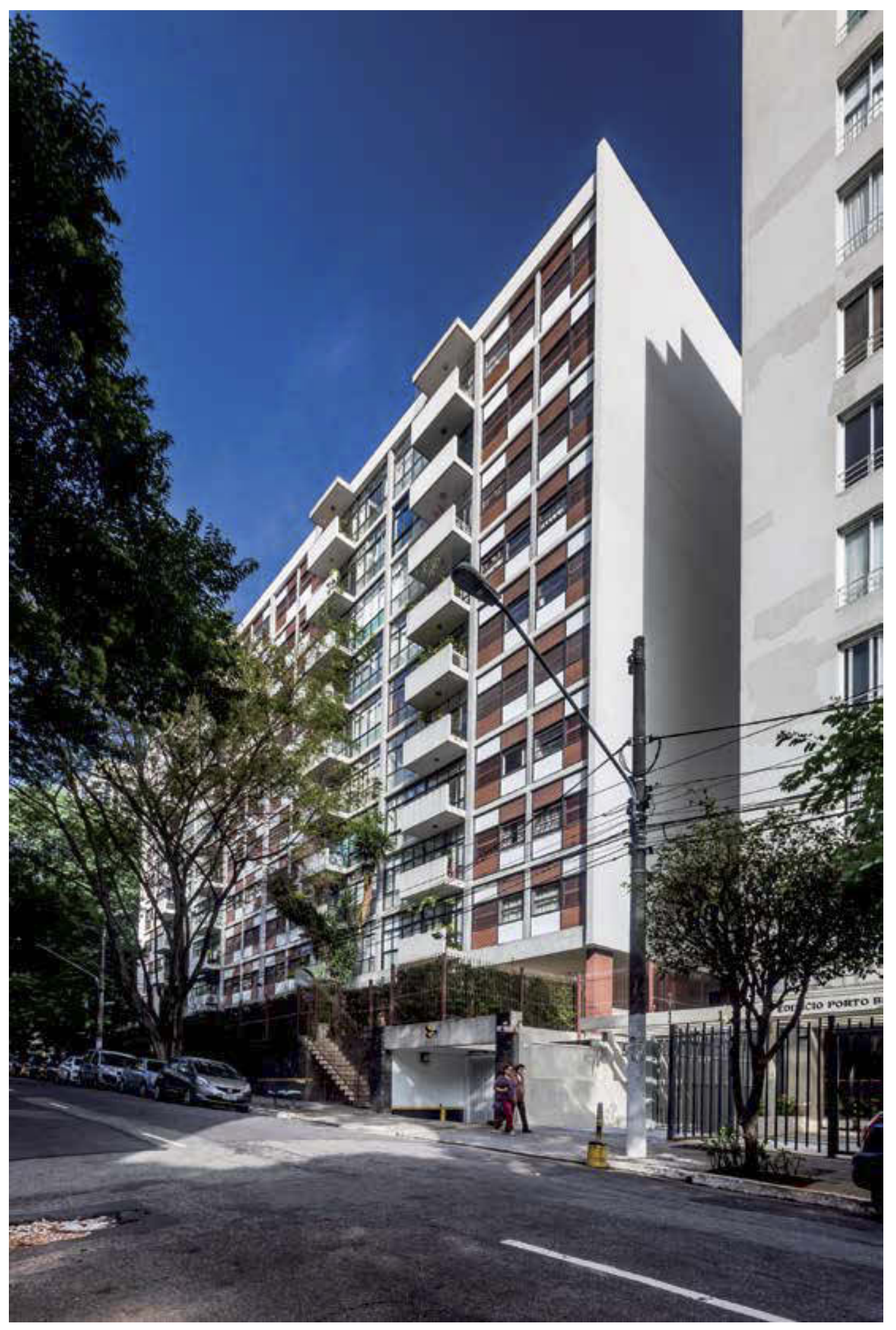


. Secretaria Geral. Conselho de Ensino, Pesquisa e Extensão. Livro de Atas de 1998 a 1999. No 59 a No 76. São Paulo: UPM, 2000.

. Secretaria Geral. Conselho de Ensino, Pesquisa e Extensão. Livro de Atas de 2000 a 2002. No 77 a No 97. São Paulo: UPM, 2003.

Regimento: Anexos. São Paulo. Universidade Mackenzie, 1991.

Catálogo Geral: Setor de Artes e Comunicação, Faculdade de Arquitetura e Urbanismo. São Paulo: Universidade Mackenzie, 1992-1994.

VIANA, M. S. R. Reflexões: breve análise curricular. Faculdade de Arquitetura e Urbanismo, 1947-1997. Universidade Mackenzie. Organização Carlos Egídio Alonso. São Paulo: Universidade Mackenzie, 1997. 
Semana Viver Metrópole, 2013. Atividades

envolvendo alunos, professores e

convidados na FAU-Mackenzie.

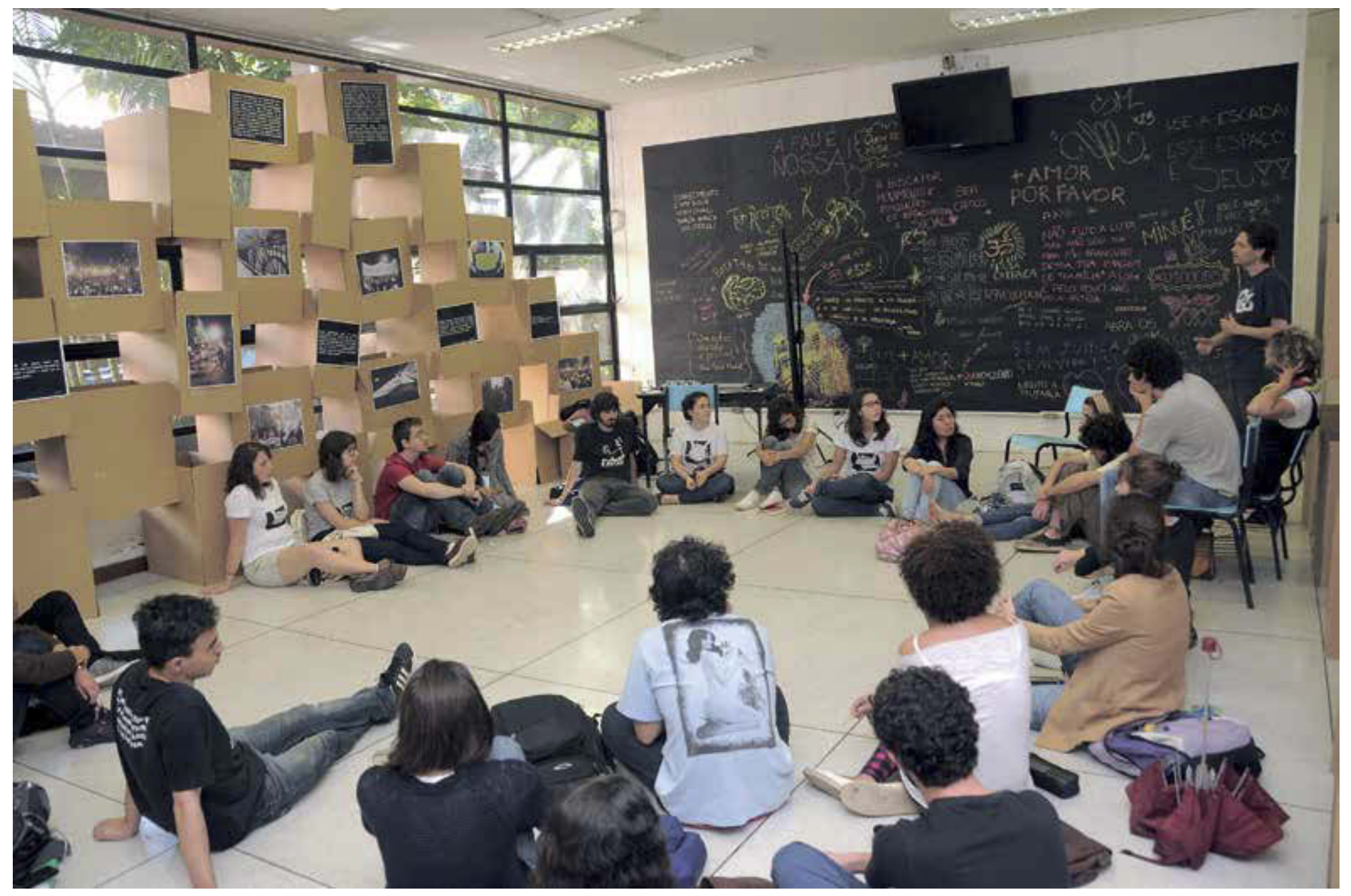

